ARTICLE

DOI: $10.1038 / s 41467-018-06020-8$

\title{
Dehydrogenative reagent-free annulation of alkenes with diols for the synthesis of saturated O-heterocycles
}

\author{
Chen-Yan Cai $^{1} \&$ Hai-Chao Xu (iD ${ }^{1}$
}

Dehydrogenative annulation reactions are among the most straightforward and efficient approach for the preparation of cyclic structures. However, the applications of this strategy for the synthesis of saturated heterocycles have been rare. In addition, reported dehydrogenative bond-forming reactions commonly employ stoichiometric chemical oxidants, the use of which reduces the sustainability of the synthesis and brings safety and environmental issues. Herein, we report an organocatalyzed electrochemical dehydrogenative annulation reaction of alkenes with 1,2- and 1,3-diols for the synthesis of 1,4-dioxane and 1,4-dioxepane derivatives. The combination of electrochemistry and redox catalysis using an organic catalyst allows the electrosynthesis to proceed under transition metal- and oxidizing reagentfree conditions. In addition, the electrolytic method has a broad substrate scope and is compatible with many common functional groups, providing an efficient and straightforward access to functionalized 1,4-dioxane and 1,4-dioxepane products with diverse substitution patterns.

\footnotetext{
${ }^{1}$ State Key Laboratory of Physical Chemistry of Solid Surfaces, Innovation Center of Chemistry for Energy Materials, and College of Chemistry and Chemica Engineering, Xiamen University, Xiamen 361005, People's Republic of China. Correspondence and requests for materials should be addressed to H.-C.X. (email: haichao.xu@xmu.edu.cn)
} 
$\mathrm{T}$ here has been mounting evidence to suggest that the number of saturated carbons and chiral centers in an organic molecule correlate strongly to its clinical prospect $^{1-4}$. Because of this, saturated heterocycles have become increasingly crucial scaffolds for the development of new pharmaceutical compounds. However, unlike heteroaromatics, which can be synthesized conveniently via a variety of cross-coupling reactions, functionalized saturated heterocyclic ring systems have remained challenging to produce ${ }^{5-7}$. For example, the generation of 1,4-dioxane derivatives, which are prevalent in natural products and bioactive compounds (Fig. 1a) ${ }^{8-13}$, usually requires a lengthy synthetic procedure and/or complex starting materials that are themselves hard to obtain $8-10,14,15$.

Annulation reactions, in which two bonds are formed in a single step, are among the most-efficient methods for the synthesis of cyclic compounds ${ }^{16}$. Particularly, dehydrogenative annulation reactions via $\mathrm{X}-\mathrm{H}(\mathrm{X}=\mathrm{C}$ or heteroatom) functionalization provide straightforward access to cyclic scaffolds from easily available substrates $^{17-19}$. Although conventional dehydrogenative annulation reactions often involve the use of stoichiometric chemical oxidants, recent advances in organic electrochemistry ${ }^{20-30}$ have led to the development of safer and more environmentally sustainable alternatives that operate under oxidant-free conditions ${ }^{31-38}$. However, to the best of our knowledge, the synthesis of saturated heterocycles with 1,4-diheteroatoms through alkene annulation reactions has not been reported. Although the intramolecular anodic dioxygenation of heteroatom-substituted alkenes proceeds efficiently ${ }^{39,40}$, the intermolecular dimethoxylation of styrenyl alkenes with $\mathrm{MeOH}$ under similar conditions resulted in a mixture of compounds generated from 1,2-addition and alkoxydimerization (Fig. 1b) ${ }^{41,42}$, probably owing to the relatively high concentration of the alkene radical cation intermediates that were formed on the electrode surface. Moreover, the dimethoxylated product can undergo oxidative decomposition via $\mathrm{C}-\mathrm{C}$ bond cleavage $\mathrm{e}^{43-46}$.

To minimize the side reactions mentioned above, we argue that the use of redox catalysis ${ }^{47-58}$ can facilitate the formation of the desired radical cation in the bulk solution and reduce the electrode potential. Herein, we report a triarylamine-catalyzed electrochemical dehydrogenative annulation reaction of alkenes with 1,2- and 1,3-diols for the synthesis of 1,4-dioxane and 1,4-dioxepane scaffolds (Fig. 1c).

\section{Results}

Reaction optimization. The annulation of 1,1-diphenylethene 1 and ethylene glycol 2 was chosen as the model reaction for optimization (Table 1). The electrolysis was conducted in an undivided cell equipped with a reticulated vitreous carbon (RVC) anode and a platinum plate cathode. The highest yield of the 1,4dioxane product 4 was $91 \%$, achieved when the reaction system consisted of triarylamine $\left(2,4-\mathrm{Br}_{2} \mathrm{C}_{6} \mathrm{H}_{3}\right)_{3} \mathrm{~N}(3)^{46,59}\left(E_{\mathrm{p} / 2}=1.48 \mathrm{~V}\right.$ vs $\mathrm{SCE}$ ) as the redox catalyst, ${ }^{i} \mathrm{PrCO}_{2} \mathrm{H}$ as acidic additive and an

a Selected bioactive 1,4-dioxane-containing compounds<smiles>CCOCC1(c2ccccc2)OCC(CO[C@H]2CN3CCC2CC3OC(C)(C)C)CO1</smiles>

Muscarinic acetylcholine<smiles>NCC1COCC(c2ccccc2)(c2ccccc2)O1</smiles>

$\mathrm{R}=\mathrm{H}, \mathrm{NMDA}$ antagonist

$\mathrm{R}=\mathrm{Bn}, \sigma_{1}$-ligand

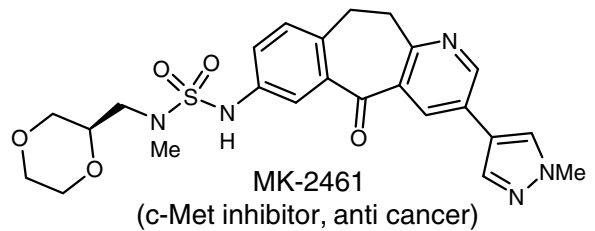

(c-Met inhibitor, anti cancer)<smiles>COc1cc(CNC(=O)c2cccc(-c3nnn(C[C@H]4CO[C@@H](CO)CO4)n3)c2)ccc1F</smiles>

b Oxidation of styrenyl alkenes using direct electrolysis

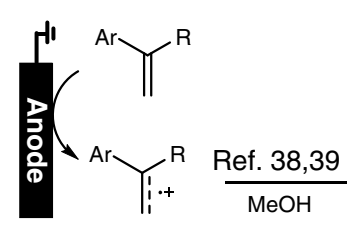<smiles>CCCCCC</smiles><smiles>[2H]C([Hg])(COC)OC</smiles>

1,2-addition

Ref. 40-43 $\downarrow$ C-C cleavage<smiles>[3H]C([3H])([3H])OC</smiles>

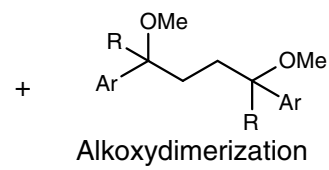

Alkoxydimerization

This work: Electrochemical dehydrogenative annulation of alkenes with diols using a redox catalyst

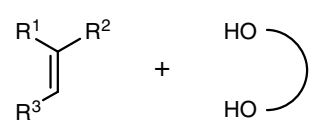

Alkenes 1,2- and 1,3-diols

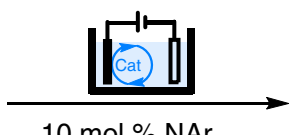

$10 \mathrm{~mol} \% \mathrm{NAr}_{3}$

Undivided cell

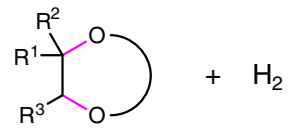

6- and 7-membered rings

Fig. 1 Reaction design. a Selected bioactive molecules containing the 1,4-dioxane moiety. b Oxidation of styrenyl alkenes via direct electrolysis. c Synthesis of O-heterocycles via annulation reactions of alkenes with diols 
Table 1 Optimization of reaction conditions ${ }^{a}$<smiles>C=C(c1ccccc1)c1ccccc1</smiles>

1

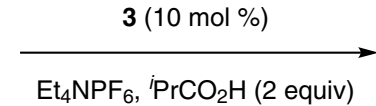

$\mathrm{MeCN}, 80^{\circ} \mathrm{C}$

"Standard conditions"

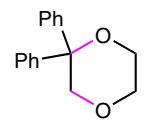

4

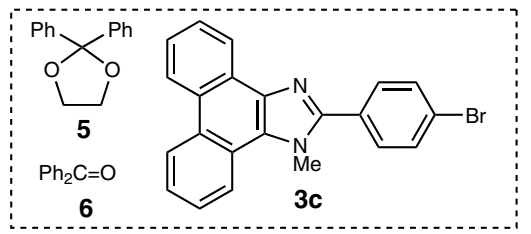

\begin{tabular}{|c|c|c|}
\hline Entry & Deviation from standard conditions & $\begin{array}{l}\text { Yield of } \\
4(\%)^{b}\end{array}$ \\
\hline 1 & None & $91^{\mathrm{C}}$ \\
\hline 2 & $\left(4-\mathrm{BrC}_{6} \mathrm{H}_{4}\right)_{3} \mathrm{~N}(\mathbf{3 a})$ as the catalyst & $5(65)$ \\
\hline 3 & $\begin{array}{l}\left.\text { (4- } \mathrm{MeO}_{2} \mathrm{CC}_{6} \mathrm{H}_{4}\right)_{3} \mathrm{~N}(\mathbf{3 b}) \text { as the } \\
\text { catalyst }\end{array}$ & $44(38)$ \\
\hline 4 & $\mathbf{3 c}$ as the catalyst & $38(25)$ \\
\hline 5 & No 3 & $58^{d}(7)$ \\
\hline 6 & Reaction at RT & 63 \\
\hline 7 & 2 equiv of $\mathbf{2}$ & $28^{e}$ \\
\hline 8 & $\mathrm{No}{ }^{i} \mathrm{PrCO}_{2} \mathrm{H}$ & 60 \\
\hline 9 & $\mathrm{AcOH}$ as the acid & 77 \\
\hline 10 & $\mathrm{EtCO}_{2} \mathrm{H}$ as the acid & 87 \\
\hline 11 & $\mathrm{CF}_{3} \mathrm{CO}_{2} \mathrm{H}$ as the acid & 78 \\
\hline 12 & $\mathrm{TsOH} \cdot \mathrm{H}_{2} \mathrm{O}$ as the acid & 80 \\
\hline 13 & Pt plate $(1 \mathrm{~cm} \times 1 \mathrm{~cm})$ as anode & 87 \\
\hline 14 & Graphite plate $(1 \mathrm{~cm} \times 1 \mathrm{~cm})$ as anode & 66 \\
\hline
\end{tabular}

excess of $\mathbf{2}$ in refluxing $\mathrm{MeCN}$ (entry 1). Other redox mediators that had a lower oxidation potential than 3 , such as (4$\left.\mathrm{BrC}_{6} \mathrm{H}_{4}\right)_{3} \mathrm{~N}\left(3 \mathbf{a}, E_{\mathrm{p} / 2}=1.06 \mathrm{~V}\right.$ vs SCE$),\left(4-\mathrm{MeO}_{2} \mathrm{CC}_{6} \mathrm{H}_{4}\right)_{3} \mathrm{~N}(3 \mathbf{b}$, $E_{\mathrm{p} / 2}=1.26 \mathrm{~V}$ vs SCE $)$ and the imidazole derivative $3 \mathrm{c}^{53}\left(E_{\mathrm{p} / 2}=\right.$ $1.19 \mathrm{~V}$ vs SCE), were less catalytically effective (entries 2-4). When no catalyst was used, the yield of 4 dropped to $58 \%$ and two additional byproducts, 5 and $\mathbf{6}$, were obtained in 16 and $6 \%$ yields, respectively (entry 5 ). Running the reaction at RT (entry 6), with only two equiv of 2 (entry 7), in the absence of ${ }^{i} \mathrm{PrCO}_{2} \mathrm{H}$ (entry 8), or with an alternative acidic additive such as $\mathrm{AcOH}$ (entry 9), $\mathrm{EtCO}_{2} \mathrm{H}$ (entry 10), $\mathrm{CF}_{3} \mathrm{CO}_{2} \mathrm{H}$ (entry 11), and $\mathrm{TsOH}$ (entry 12), all led to a significant decrease in reaction efficiency. The replacement of RVC with an anode material that had a smaller surface area, such as Pt (entry 13) or graphite (entry 14), also showed a detrimental effect on the formation of $\mathbf{4}$.

Substrate scope. We explored the substrate scope under the optimized conditions by first varying the substituents on the alkene (Table 2). The reaction was shown to be broadly compatible with different 1,1-diphenyl alkenes bearing substituents of diverse electronic properties at the para- or meta-position of the benzene ring (7-14). Meanwhile, alkenes functionalized with a 2thiophenyl or 2-thiazolyl group were also tolerated $(\mathbf{1 5}, \mathbf{1 6})$, albeit with slightly decreased reactivity. When a trisubstituted olefin whose $\mathrm{C}-\mathrm{C}$ double bond was embedded in a five or six-membered ring was employed, the reaction afforded the cis-fused products $(\mathbf{1 7 - 1 9 )}$ as the only diastereomer. However, the employment of a seven-membered cyclic alkene resulted in the generation of a mixture of diastereomers $(\mathbf{2 0}, \mathrm{dr}=1.8: 1)$. The structure of the minor diastereomer of $\mathbf{2 0}$ was subsequently confirmed by X-ray crystallographic analysis. Trisubstituted acyclic alkenes (21-31) bearing a halogen $(\mathbf{2 3}, \mathbf{2 4})$, free alcohol $(\mathbf{2 5})$, silyl ether (26), tosylate (27), ester (28), sulfonamide (29,30), or phthalimide (31) were all found to be suitable substrates. Furthermore, dioxanes $\mathbf{3 2}$ and 33 could be obtained in moderate yields from their corresponding enyne and diene precursors, respectively. It is worth emphasizing that a previous attempt at the anodic reaction of dienes with ethylene glycol generated a mixture of addition and dimerization products instead of the annulation product ${ }^{60}$. Current limitation of the annulation reaction included the inefficient reaction of $\alpha$-methylstyrene (34,19\% yield) and the complete failure of styrene (35) and a tetrasubstituted alkene (36)

On the other hand, ethylene glycol could be replaced with other vicinal diols such as $(2 R, 3 R)-(-)-2,3$-butanediol (37), cis1,2-cyclohexanediol (38), 2-methyl-1,2-propanediol (39, 40), 2,3dimethyl-2,3-butanediol (41), and 1,3-diols (42-45). Notably, the unsymmetrically substituted diol 2-methyl-1,2-propanediol reacted regioselectively with different trisubstituted alkenes to afford 39 and $\mathbf{4 0}$ bearing two tetrasubstituted carbon centers.

The electrochemical annulation reaction could be conducted on a gram scale as demonstrated by the preparation of $2.5 \mathrm{~g}$ of $\mathbf{2 7}$ in $80 \%$ yield from the annulation of the alkene $\mathbf{4 6}$ and $\mathbf{2}$ (Fig. 2). To allow the application of a higher current, a large anode 50 times the size of that used for the abovementioned model reaction was employed. Gratifyingly, the reaction was completed in < 1 hour, which provided rapid access to 27 .

\section{Discussion}

A reaction mechanism was proposed in Fig. 3a. The triarylamine catalyst $3\left(E_{\mathrm{p} / 2}=1.48 \mathrm{~V}\right.$ vs SCE $)$ is first anodically oxidized into the radical cation $\mathbf{I}$, which in turn oxidizes the alkene substrate $\mathbf{1}$ $\left(E_{\mathrm{p} / 2}=1.68 \mathrm{~V}\right.$ vs SCE) through single-electron transfer to furnish 
ARTICLE

NATURE COMMUNICATIONS | DOI: 10.1038/s41467-018-06020-8

Table 2 Substrate scope

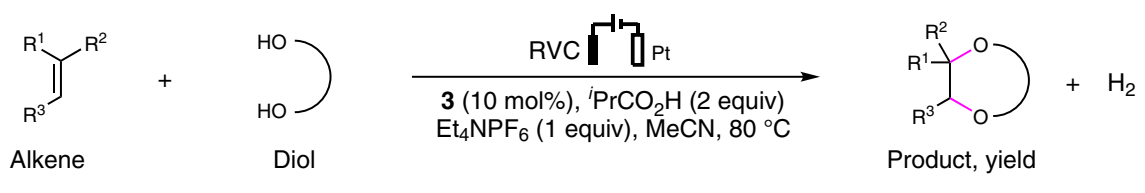

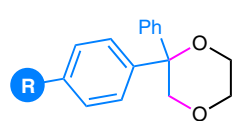

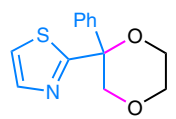

$16,40 \%^{\mathrm{b}}$

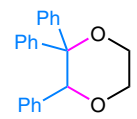

21, $41 \%$

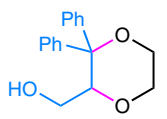

$25,66 \%$

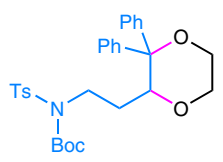

$30,69 \%$

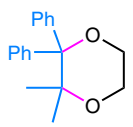

$36,0 \%$

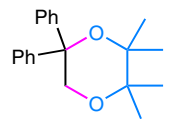

41, $47 \%$
7, $\mathrm{R}=\mathrm{Me}, 72 \%$

8, $R=F, 64 \%$

9, $\mathrm{R}=\mathrm{Cl}, 73 \%$

10, $R=B r, 56 \%$

$11, \mathrm{R}=\mathrm{CN}, 62 \%$

$12, \mathrm{R}=\mathrm{CO}_{2} \mathrm{Me}, 58 \%$
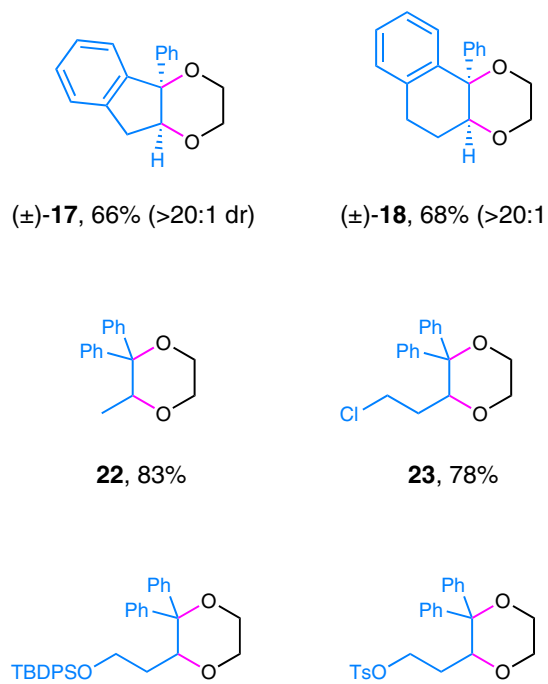

26, $59 \%$

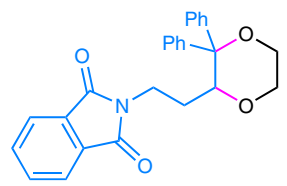

31, $75 \%$

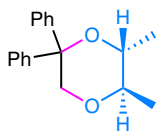

(+)-37, $72 \%$

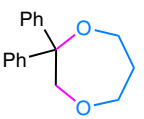

42, $55 \%$

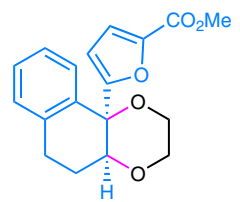

$( \pm)-18,68 \%(>20: 1 d r)$

$( \pm)-19,69 \%(>20: 1 d r)$
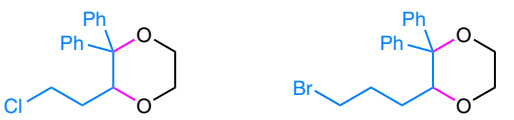

$23,78 \%$

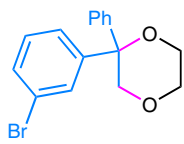

$14,61 \%$

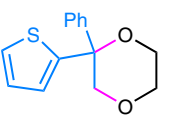

$15,42 \%^{b}$

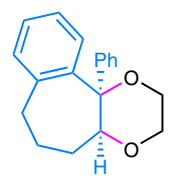

$( \pm)-20,64 \%(1.8: 1 \mathrm{dr})$

$24,53 \%$
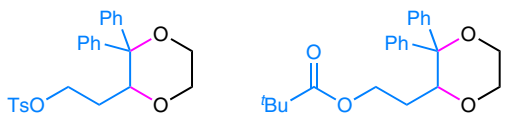

28, $65 \%$
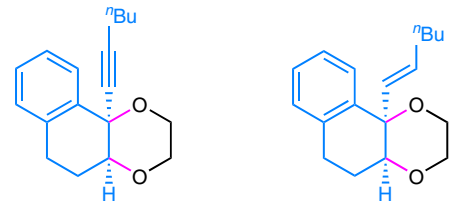

$( \pm)-32,60 \%{ }^{b}(>20: 1 \mathrm{dr})$

$( \pm)-33,51 \%^{\mathrm{b}}(>20: 1 \mathrm{dr})$
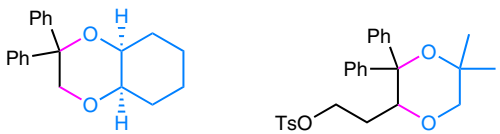

( \pm - $-38,70 \%$

$39,52 \%^{\mathrm{c}}$
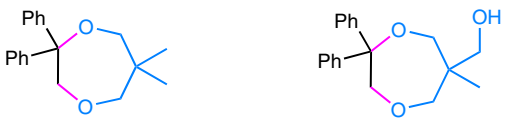

$44,36 \%$
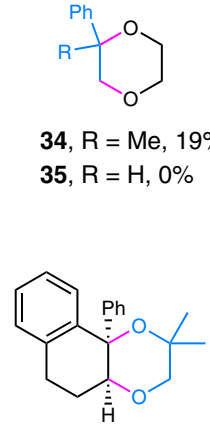

34, $\mathrm{R}=\mathrm{Me}, 19 \%$ 35, $\mathrm{R}=\mathrm{H}, 0 \%$

$( \pm)-40,45 \%$ b,c $(>20: 1 d r)$

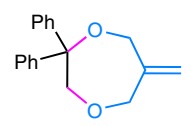

$45,55 \%$

TBDPS, tert-butyldiphenylsilyl; Ts, p-toluenesulfonyl; Boc, tert-butyloxycarbonyl

aReaction conditions: Alkene $(0.2 \mathrm{mmol})$, diol $(9 \mathrm{mmol}), 1.7-4.5 \mathrm{~h}$. All yields are isolated yields

${ }^{\mathrm{b}} \mathrm{MeCN} / \mathrm{CH}_{2} \mathrm{Cl}_{2}$ (1:2) as solvent

${ }^{\mathrm{c}} 18 \mathrm{mmol}$ of diol was employed

4

NATURE COMMUNICATIONS | (2018)9:3551|DOI: 10.1038/s41467-018-06020-8 | www.nature.com/naturecommunications 
the corresponding radical cation II and regenerate 3 . The nucleophilic trapping of II with ethylene glycol (2) and the subsequent deprotonation produce the carbon-centered radical III $^{39,40,61-63}$, which is then oxidized by I to afford the carbon cation IV. The cyclization of IV eventually generates the 1,4dioxane product $4\left(E_{\mathrm{p} / 2}=1.95 \mathrm{~V}\right.$ vs $\left.\mathrm{SCE}\right)$. On the cathode, protons are reduced to produce $\mathrm{H}_{2}$. The addition of ${ }^{i} \mathrm{PrCO}_{2} \mathrm{H}$ facilitates $\mathrm{H}_{2}$ evolution and probably also plays an important role in reducing unwanted reduction of $\mathbf{I}$, the $\mathrm{CH}_{2} \mathrm{Cl}_{2}$ solvent and the alkene substrate. The catalytic role of 3 was confirmed by the detection of a catalytic current ${ }^{47,64}$ using cyclic voltammetry (Fig. 3b). The inclusion of 3 was also found to inhibit the oxidative decomposition of $\mathbf{4}$, probably because of the inefficient oxidation of $\mathbf{4}$ by $\mathbf{3}$-derived radical cation I (Supplementary

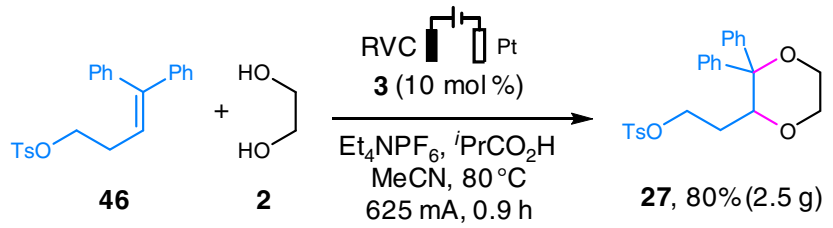

Fig. 2 Electrochemical gram scale reaction. Gram scale synthesis of $\mathbf{2 7}$
Fig. 1). This was supported by the observation that 4 remained largely stable when subjected to electrolysis in the presence of a catalytic amount of 3 (Fig. 4a). In contrast, under similar conditions but in the absence of $3,32 \%$ of 4 was found to have decomposed, resulting in the formation of 1,3-dioxane 5 and benzophenone 6 in 16 and 7\% yields, respectively (Fig. 4b).

In summary, we have developed a triarylamine-catalyzed electrochemical annulation reaction for the synthesis of 1,4dioxane and 1,4-dioxepane scaffolds from alkenes and diols. The reaction is compatible with a wide variety of functional groups and showed excellent tolerance for di- and trisubstituted alkenes, allowing facile access to functionalized O-heterocycles with tetrasubstituted carbon centers. We are currently investigating whether our alkene annulation reaction can be applied to the synthesis of other 1,4-heterocyclic compounds.

\section{Methods}

Representative procedure for the synthesis of 4. A $10-\mathrm{mL}$ three-necked roundbottomed flask was charged with $3(0.02 \mathrm{mmol}, 0.1$ equiv), the alkene $1(0.2 \mathrm{mmol}$, 1 equiv), ethylene glycol 2 (9 mmol, 45 equiv), ${ }^{i} \mathrm{PrCO}_{2} \mathrm{H}(0.4 \mathrm{mmol}, 2$ equiv), and $\mathrm{Et}_{4} \mathrm{NPF}_{6}(0.2 \mathrm{mmol}, 1$ equiv). The flask was equipped with a reflux condenser, a RVC anode (100 PPI (pores per inch), $\sim 65 \mathrm{~cm}^{2} \mathrm{~cm}^{-3}, 1 \mathrm{~cm} \times 1 \mathrm{~cm} \times 1.2 \mathrm{~cm}$ ) and a platinum plate $(1 \mathrm{~cm} \times 1 \mathrm{~cm})$ cathode before being flushed with argon. Then, anhydrous MeCN was added. Constant current $\left(12.5 \mathrm{~mA}, j_{\text {anode }}=0.16 \mathrm{~mA} \mathrm{~cm}^{-2}\right)$ electrolysis was performed at reflux (internal temperature, $80^{\circ} \mathrm{C}$ ) until the alkene a

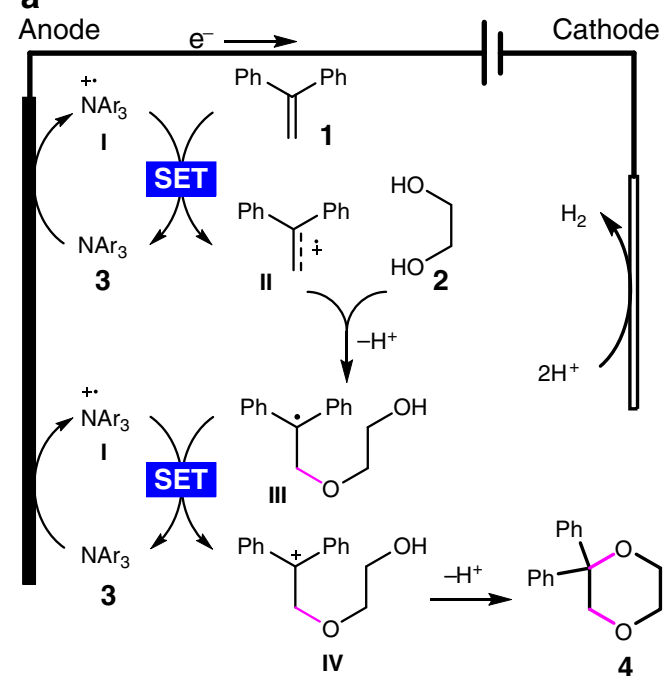

b

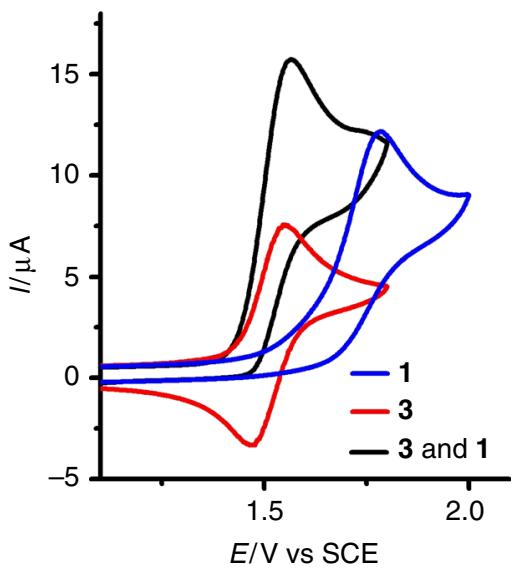

Fig. 3 Mechanistic rationale and cyclic voltammograms. a Mechanistic proposal. b Cyclic voltammograms recorded in $\mathrm{MeCN} \mathrm{CH} \mathrm{Cl}_{2}(6: 1)$ with $0.1 \mathrm{M}$ $\mathrm{Et}_{4} \mathrm{NPF}_{6}$ as the supporting electrolyte. $3(2.6 \mathrm{mM}) . \mathbf{1}(1.3 \mathrm{mM})$. SET, single-electron transfer

a
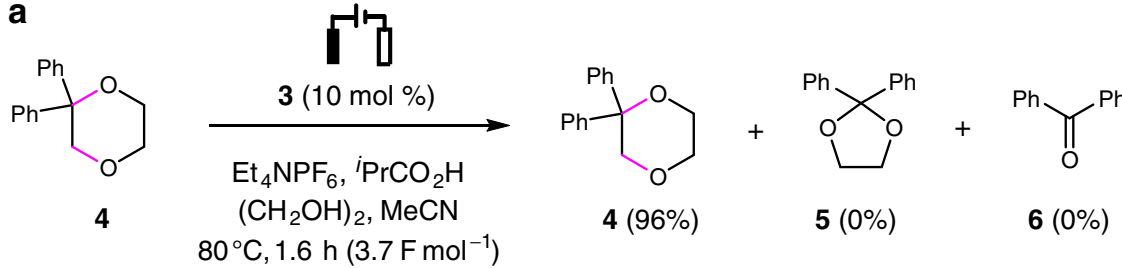

b<smiles>c1ccc([C@H]2COCCO2)cc1</smiles>

4

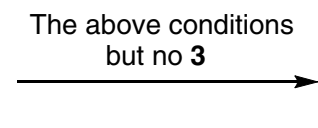

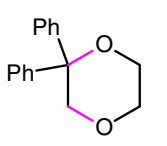

$4(68 \%)$

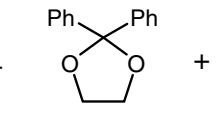

$5(16 \%)$<smiles>O=C(c1ccccc1)c1ccccc1</smiles>

$6(7 \%)$

Fig. 4 Electrolysis of compound 4. a Electrolysis of $\mathbf{4}$ in the presence of triarylamine 3. $\mathbf{b}$ electrolysis of $\mathbf{4}$ in the absence of $\mathbf{3}$. Yields were determined by ${ }^{1} \mathrm{H}$ NMR using 1,3,5-trimethoxygenzene as the internal standard 
substrate was completely consumed (monitored by thin layer chromatography or ${ }^{1} \mathrm{H}$ NMR). The reaction mixture was cooled to room temperature (RT) and saturated $\mathrm{Na}_{2} \mathrm{CO}_{3}$ solution was added. The resulting mixture was extracted with EtOAc $(3 \times 20 \mathrm{~mL})$. The combined organic solution was dried with anhydrous $\mathrm{MgSO}_{4}$ and concentrated under reduced pressure. The residue was chromatographed through silica gel and the product $\mathbf{4}$ was obtained in $91 \%$ yield as a white solid by eluting with ethyl acetate/hexanes. All new compounds were fully characterized (See the Supplementary Information).

Procedure for the gram scale synthesis of 27. The gram scale synthesis of compound $27(80 \%, 2.5 \mathrm{~g})$ was conducted in a $200-\mathrm{mL}$ beaker-type cell with two RVC plates (100 PPI, $5 \mathrm{~cm} \times 5 \mathrm{~cm} \times 1.2 \mathrm{~cm}$ ) as anode and a Pt plate cathode ( 3 $\mathrm{cm} \times 3 \mathrm{~cm})$ at constant current of $625 \mathrm{~mA}\left(j_{\text {anode }}=0.16 \mathrm{~mA} \mathrm{~cm}^{-2}\right)$ for $0.9 \mathrm{~h}$. The reaction mixture consisted of compound $2(15 \mathrm{~mL}, 262 \mathrm{mmol}), 46(2.2 \mathrm{~g}, 5.8$ $\mathrm{mmol}), 3(0.42 \mathrm{~g}, 0.58 \mathrm{mmol}),{ }^{i} \mathrm{PrCO}_{2} \mathrm{H}(1.1 \mathrm{~mL}, 11.6 \mathrm{mmol}), \mathrm{MeCN}(180 \mathrm{~mL})$, and $\mathrm{Et}_{4} \mathrm{NPF}_{6}(1.6 \mathrm{~g}, 5.8 \mathrm{mmol})$

\section{Data availability}

The X-ray crystallographic coordinates for structures reported in this article have been deposited at the Cambridge Crystallographic Data Centre (CCDC), under deposition number CCDC 1841113 (20). The data can be obtained free of charge from The Cambridge Crystallographic Data Centre [http://www.ccdc.cam.ac.uk/data_request/cif]. The data supporting the findings of this study are available within the article and its Supplementary Information files. Any further relevant data are available from the authors on request.

Received: 16 June 2018 Accepted: 10 August 2018

Published online: 03 September 2018

\section{References}

1. Lovering, F. Escape from flatland 2: complexity and promiscuity. Med. Chem. Commun. 4, 515-519 (2013).

2. Lovering, F., Bikker, J. \& Humblet, C. Escape from flatland: increasing saturation as an approach to improving clinical success. J. Med. Chem. 52, 6752-6756 (2009).

3. Ritchie, T. J., Macdonald, S. J. F., Young, R. J. \& Pickett, S. D. The impact of aromatic ring count on compound developability: further insights by examining carbo- and hetero-aromatic and -aliphatic ring types. Drug Discov. Today 16, 164-171 (2011).

4. Morley, A. D. et al. Fragment-based hit identification: thinking in 3D. Drug Discov. Today 18, 1221-1227 (2013).

5. Over, B. et al. Natural-product-derived fragments for fragment-based ligand discovery. Nat. Chem. 5, 21-28 (2012).

6. Vo, C.-V. T., Luescher, M. U. \& Bode, J. W. SnAP reagents for the one-step synthesis of medium-ring saturated $\mathrm{N}$-heterocycles from aldehydes. Nat. Chem. 6, 310-314 (2014).

7. Ye, Z., Adhikari, S., Xia, Y. \& Dai, M. Expedient syntheses of N-heterocycles via intermolecular amphoteric diamination of allenes. Nat. Commum. 9, 721 (2018).

8. Del Bello, F. et al. Novel muscarinic acetylcholine receptor hybrid ligands embedding quinuclidine and 1,4-dioxane fragments. Eur. J. Med. Chem. 137, 327-337 (2017).

9. Del Bello, F. et al. 1,4-dioxane, a suitable scaffold for the development of novel M3 muscarinic receptor antagonists. J. Med. Chem. 55, 1783-1787 (2012).

10. Bonifazi, A. et al. Novel potent N-methyl-d-aspartate (NMDA) receptor antagonists or $\sigma 1$ receptor ligands based on properly substituted 1,4-dioxane ring. J. Med. Chem. 58, 8601-8615 (2015).

11. Liu, T. et al. Synthetic silvestrol analogues as potent and selective protein synthesis inhibitors. J. Med. Chem. 55, 8859-8878 (2012).

12. Katz, J. D. et al. Discovery of a $5 H$-benzo[4,5]cyclohepta[1,2-b]pyridin-5-one (MK-2461) inhibitor of c-Met kinase for the treatment of cancer. J. Med. Chem. 54, 4092-4108 (2011).

13. Ruminski, P. G. et al. Discovery of N-(4-fluoro-3-methoxybenzyl)-6-(2(((2S,5R)-5-(hydroxymethyl)-1,4-dioxan-2-yl)methyl)-2H-tetrazol-5-yl)-2methylpyrimidine-4-carboxamide. A highly selective and orally bioavailable matrix metalloproteinase-13 inhibitor for the potential treatment of osteoarthritis. J. Med. Chem. 59, 313-327 (2016).

14. Yang, W. \& Sun, J. Organocatalytic enantioselective synthesis of 1,4-dioxanes and other oxa-heterocycles by oxetane desymmetrization. Angew. Chem. Int. Ed. 128, 1900-1903 (2016)

15. Tiecco, M. et al. Synthesis of enantiomerically pure 1,4-dioxanes from alkenes promoted by organoselenium reagents. Tetrahedron: Asymmetry 14, 1095-1102 (2003).
16. Molander, G. A. Diverse methods for medium ring synthesis. Acc. Chem. Res 31, 603-609 (1998).

17. Moisés, G. \& Luis, M. J. Metal-catalyzed annulations through activation and cleavage of C-H bonds. Angew. Chem. Int. Ed. 55, 11000-11019 (2016).

18. Ackermann, L. Carboxylate-assisted ruthenium-catalyzed alkyne annulations by C-H/het-H bond functionalizations. Acc. Chem. Res. 47, 281-295 (2014).

19. Hou, Z.-W., Mao, Z.-Y. \& Xu, H.-C. Recent progress on the Synthesis of (aza) indoles through oxidative alkyne annulation reactions. Synlett 28, 1867-1872 (2017).

20. Yoshida, J., Kataoka, K., Horcajada, R. \& Nagaki, A. Modern strategies in electroorganic synthesis. Chem. Rev. 108, 2265-2299 (2008).

21. Yan, M., Kawamata, Y. \& Baran, P. S. Synthetic organic electrochemical methods since 2000: on the verge of a renaissance. Chem. Rev. 117, 13230-13319 (2017).

22. Jiang, Y., Xu, K. \& Zeng, C. Use of electrochemistry in the synthesis of heterocyclic structures. Chem. Rev. 118, 4485-4540 (2018).

23. Anton, W. et al. Electrifying organic synthesis. Angew. Chem. Int. Ed. 57, 5594-5619 (2018).

24. Tang, S., Liu, Y. \& Lei, A. Electrochemical oxidative cross-coupling with hydrogen evolution: a green and sustainable way for bond formation. Chem $\mathbf{4}$, 27-45 (2018).

25. Yang, Q. L., Fang, P. \& Mei, T. S. Recent advances in organic electrochemical C-H functionalization. Chin. J. Chem. 36, 338-352 (2018)

26. Yoshida, J.-i, Shimizu, A. \& Hayashi, R. Electrogenerated cationic reactive intermediates: the pool method and further advances. Chem. Rev. 118, $4702-4730$ (2018).

27. Moeller, K. D. Using physical organic chemistry to shape the course of electrochemical reactions. Chem. Rev. 118, 4817-4833 (2018).

28. Sauermann, N., Meyer, T. H., Qiu, Y. \& Ackermann, L. Electrocatalytic C-H activation. ACS Catal. 8, 7086-7103 (2018).

29. Ma, C., Fang, P. \& Mei, T.-S. Recent advances in C-H functionalization using electrochemical transition metal catalysis. ACS Catal. 8, 7179-7189 (2018).

30. Kärkäs, M. D. Electrochemical strategies for $\mathrm{C}-\mathrm{H}$ functionalization and $\mathrm{C}-\mathrm{N}$ bond formation. Chem. Soc. Rev. 47, 5786-5865 (2018).

31. Liu, K., Tang, S., Huang, P. \& Lei, A. External oxidant-free electrooxidative [3 +2 ] annulation between phenol and indole derivatives. Nat. Commun. 8, 775 (2017).

32. Zhang, G. et al. Oxidative [4+2] annulation of styrenes with alkynes under external-oxidant-free conditions. Nat. Commun. 9, 1225 (2018).

33. Cong, T., \& Leonardo, M., \& TH, M., \& Lutz, A. Electrochemical C-H/N-H activation by water-tolerant cobalt catalysis at room temperature. Angew. Chem. Int. Ed. 57, 2383-2387 (2018).

34. Youai, Q., Cong, T., Leonardo, M., Torben, R. \& Lutz, A. Electrooxidative ruthenium-catalyzed $\mathrm{C}-\mathrm{H} / \mathrm{O}-\mathrm{H}$ annulation by weak $\mathrm{O}$-coordination. Angew. Chem. Int. Ed. 57, 5818-5822 (2018).

35. Xu, F., Li, Y.-J., Huang, C. \& Xu, H.-C. Ruthenium-catalyzed electrochemical dehydrogenative alkyne annulation. ACS Catal. 8, 3820-3824 (2018).

36. Hou, Z. W. et al. Electrochemical C-H/N-H functionalization for the synthesis of highly functionalized (aza)indoles. Angew. Chem. Int. Ed. 55, 9168-9172 (2016).

37. Chen, J. et al. Electrocatalytic aziridination of alkenes mediated by $n-\mathrm{Bu}_{4} \mathrm{NI}$ : a radical pathway. Org. Lett. 17, 986-989 (2015).

38. Jin, L. et al. Electrochemical aziridination by alkene activation using a sulfamate as the nitrogen source. Angew. Chem. Int. Ed. 57, 5695-5698 (2018).

39. Liu, B., Duan, S., Sutterer, A. C. \& Moeller, K. D. Oxidative cyclization based on reversing the polarity of enol ethers and ketene dithioacetals. Construction of a tetrahydrofuran ring and application to the synthesis of $(+)$-nemorensic acid. J. Am. Chem. Soc. 124, 10101-10111 (2002).

40. Sun, Y., Liu, B., Kao, J., d'Avignon, D. A. \& Moeller, K. D. Anodic cyclization reactions: reversing the polarity of ketene dithioacetal groups. Org. Lett. 3, 1729-1732 (2001)

41. Engels, R., Schäfer Hans, J. \& Steckhan, E. Anodische oxidation von arylolefinen. Liebigs Ann. Chem. 1977, 204-224 (1977).

42. Kojima, M., Sakuragi, H. \& Tokumaru, K. Electrochemical oxidation of aromatic olefins. Dependence of the reaction course on the structure of the olefins and on the nature of the anodes. Chem. Lett. 10, 1707-1710 (1981).

43. Ogibin, Y. N., Ilovaisky, A. I. \& Nikishin, G. I. Electrochemical cleavage of double bonds in conjugated cycloalkenyl- and 1,2-alkenobenzenes. J. Org. Chem. 61, 3256-3258 (1996).

44. Ogibin, Y. N., Sokolov, A. B., Ilovaiskii, A. I., Élinson, M. N. \& Nikishin, G. I. Electrochemical cleavage of the double bond of 1-alkenylarenes. Bull. Acad. Sci. USSR Div. Chem. Soc. 40, 561-566 (1991).

45. Okajima, M., Suga, S., Itami, K. \& Yoshida, J.-i "Cation pool" method based on $\mathrm{C}-\mathrm{C}$ bond dissociation. Effective generation of monocations and dications. $J$ Am. Chem. Soc. 127, 6930-6931 (2005).

46. Wu, X., Davis, A. P. \& Fry, A. J. Electrocatalytic oxidative cleavage of electrondeficient substituted stilbenes in acetonitrile-water employing a new high 
oxidation potential electrocatalyst. An electrochemical equivalent of ozonolysis. Org. Lett. 9, 5633-5636 (2007).

47. Francke, R. \& Little, R. D. Redox catalysis in organic electrosynthesis: basic principles and recent developments. Chem. Soc. Rev. 43, 2492-2521 (2014)

48. Steckhan, E. Indirect electroorganic syntheses - a modern chapter of organic electrochemistry. Angew. Chem. Int. Ed. 25, 683-701 (1986).

49. Nutting, J. E., Rafiee, M. \& Stahl, S. S. Tetramethylpiperidine N-oxyl (TEMPO), phthalimide N-oxyl (PINO), and related N-oxyl species: electrochemical properties and their use in electrocatalytic reactions. Chem. Rev. 118, 4834-4885 (2018).

50. Fu, N., Sauer, G. S., Saha, A., Loo, A. \& Lin, S. Metal-catalyzed electrochemical diazidation of alkenes. Science 357, 575-579 (2017).

51. Badalyan, A. \& Stahl, S. S. Cooperative electrocatalytic alcohol oxidation with electron-proton-transfer mediators. Nature 535, 406-410 (2016).

52. Zeng, C.-C., Zhang, N.-T., Lam, C. M. \& Little, R. D. Novel triarylimidazole redox catalysts: synthesis, electrochemical properties, and applicability to electrooxidative C-H activation. Org. Lett. 14, 1314-1317 (2012).

53. Francke, R. \& Little, R. D. Optimizing electron transfer mediators based on arylimidazoles by ring fusion: Synthesis, electrochemistry, and computational analysis of 2-aryl-1-methylphenanthro[9,10-d]imidazoles. J. Am. Chem. Soc. 136, 427-435 (2014).

54. Horn, E. J. et al. Scalable and sustainable electrochemical allylic C-H oxidation. Nature 533, 77-81 (2016).

55. Philipp, R., Steffen, E., Alexander, K. C. \& Gerhard, H. Efficient oxidative coupling of arenes via electrochemical regeneration of 2,3-dichloro-5,6dicyano-1,4-benzoquinone (DDQ) under mild reaction conditions. $A d v$. Synth. Catal. 359, 1359-1372 (2017).

56. Hou, Z.-W., Mao, Z.-Y., Melcamu, Y. Y., Lu, X. \& Xu, H.-C. Electrochemical synthesis of imidazo-fused $\mathrm{N}$-heteroaromatic compounds through a $\mathrm{C}-\mathrm{N}$ bond-forming radical cascade. Angew. Chem. Int. Ed. 57, 1636-1639 (2018).

57. Kawamata, Y. et al. Scalable, electrochemical oxidation of unactivated $\mathrm{C}-\mathrm{H}$ bonds. J. Am. Chem. Soc. 139, 7448-7451 (2017).

58. Rafiee, M., Wang, F., Hruszkewycz, D. P. \& Stahl, S. S. Nhydroxyphthalimide-mediated electrochemical iodination of methylarenes and comparison to electron-transfer-initiated $\mathrm{C}-\mathrm{H}$ functionalization. J. Am. Chem. Soc. 140, 22-25 (2018).

59. Shen, Y., Hattori, H., Ding, K., Atobe, M. \& Fuchigami, T. Triarylamine mediated desulfurization of S-arylthiobenzoates and a tosylhydrazone derivative. Electrochim. Acta 51, 2819-2824 (2006).

60. Baltes, H., Stork, L. \& Schäfer, H. J. Anodische oxidation organischer verbindungen, 23 anodische addition von harnstoffen und ethylenglykol an konjugierte diene. Liebigs Ann. Chem. 1979, 318-327 (1979).

61. Yi, H. et al. Photocatalytic dehydrogenative cross-coupling of alkenes with alcohols or azoles without external oxidant. Angew. Chem. Int. Ed. 56, 1120-1124 (2017).

62. Wilger, D. J., Grandjean, J.-M. M., Lammert, T. R. \& Nicewicz, D. A. The direct anti-Markovnikov addition of mineral acids to styrenes. Nat. Chem. 6, $720(2014)$
63. Johnston, L. J. \& Schepp, N. P. Reactivities of radical cations: characterization of styrene radical cations and measurements of their reactivity toward nucleophiles. J. Am. Chem. Soc. 115, 6564-6571 (1993).

64. Wu, Z. J. \& Xu, H.-C. Synthesis of C3-fluorinated oxindoles through reagentfree cross-dehydrogenative coupling. Angew. Chem. Int. Ed. 56, 4734-4738 (2017).

\section{Acknowledgements}

We acknowledge the financial support of this research from MOST (2016YFA0204100), NSFC (No. 21672178), the "Thousand Youth Talents Plan", and Fundamental Research Funds for the Central Universities.

\section{Author contributions}

C.Y.C. performed the experiments and analyzed the data. H.C.X. designed and directed the project and wrote the manuscript.

\section{Additional information}

Supplementary Information accompanies this paper at https://doi.org/10.1038/s41467 018-06020-8.

Competing interests: The authors declare no competing interests.

Reprints and permission information is available online at http://npg.nature.com/ reprintsandpermissions/

Publisher's note: Springer Nature remains neutral with regard to jurisdictional claims in published maps and institutional affiliations.

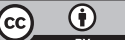

Open Access This article is licensed under a Creative Commons Attribution 4.0 International License, which permits use, sharing, adaptation, distribution and reproduction in any medium or format, as long as you give appropriate credit to the original author(s) and the source, provide a link to the Creative Commons license, and indicate if changes were made. The images or other third party material in this article are included in the article's Creative Commons license, unless indicated otherwise in a credit line to the material. If material is not included in the article's Creative Commons license and your intended use is not permitted by statutory regulation or exceeds the permitted use, you will need to obtain permission directly from the copyright holder. To view a copy of this license, visit http://creativecommons.org/ licenses/by/4.0/.

(C) The Author(s) 2018 